\title{
Evaluation of Wheat Genotypes for Resistance against Foliar Blight Disease
}

\author{
Ghanshyam Verma*, Shivam Kumar, Chandra Pal and Sheetala Varma \\ Department of Plant Pathology, Narendra Deva University of Agriculture \& Technology, \\ Kumarganj, Faizabad (U.P.) - 224229, India \\ *Corresponding author
}

\begin{abstract}
A B S T R A C T
Keywords

Spot blotch of wheat, Symptoms, Stock culture,

Varietal screening, Yield losses

\section{Article Info}

Accepted:

12 October 2018

Available Online:

10 November 2018

Foliar blight disease caused by Bipolaris sorokiniana (Sacc.) Shoem is most important disease of wheat in North Eastern plain zones (NEPZ) representing warm and humid climate in India. It is also increasing in North Western plains zones (NWPZ), due to climate changes and causes considerable losses in susceptible varieties. A field study was conducted during Rabi, 2014-15 and 2015-16 crop seasons at Main Experiment Station, Narendradev University of Agriculture and Technology, Kumarganj, Faizabad to test the resistance of 250 genotypes against Bipolaris sorokiniana under artificial epiphytotics conditions. Each genotype was sown in last week of November in single row of one meter length. Variety Raj 4015 was used as check and was sown after every 20 genotypes. Pure culture of Bipolaris sorokiniana was inoculated on genotypes by using cleaned sprayer, at evening. Disease data was recorded using double digit scale based on per cent blighted area on flag leaf and one leaf just below. Out of 300 genotypes, no any genotype found immune, 29 genotypes were found resistant, 132 were moderately resistant, 103 were moderately susceptible and 37 were found susceptible against spot blotch disease of wheat.
\end{abstract}

\section{Introduction}

Wheat (Triticum aestivum L.) belongs to the family Poaceae. It is the most important cereal crop after rice in India and is the most important food of about two billion people (36\% of the world population). The common bread wheat, $T$. aestivum, is the most important species, occupying more than $90 \%$ of the wheat area and $87 \%$ of the total wheat production in the country. In world, Wheat is grown over 224.7 million hectare area with production of 734.80 million metric tons and yield of 3.27 metric tons per hectare. In India, wheat is grown over 31.47 million hectare area with production of 86.53 million metric tons and yield of 2.75 metric tons per hectare (Anonymous, 2016) about $91 \%$ of the total wheat production is contributed by northern states. Among them, Uttar Pradesh rank first with respect to area (9.645 m.ha.) and production of (30.00 m.t.) but the average productivity $(27.86 \mathrm{q} / \mathrm{ha})$ is much lower as compare to Punjab and Haryana (Anonymous, 2016). Wheat is nature's unique gift to mankind as it is an excellent source of nutrition.

Spot blotch caused by Bipolaris sorokiniana (Sacc.) Shoem. (syn. Helminthosporium 
sativum, teleomorph Cochliobolous sativus) is an important wheat disease in warmer and humid growing regions of the world such as Eastern India, South East Asia (Joshi et al., 2007). Yield losses were estimated to be 18-22 per cent in India (Saari, 1998). The control strategy for the diseases caused by $B$. sorokiniana is based on an integrated approach where genetic resistance is a major element, because economic returns have not always resulted in commercial grain production from fungicide inputs (Duveiller and Sharma, 2009). Hence, search of effective non-fungicidal control of spot blotch disease is of utmost importance. The best, long term, economically and environmentally safe method for sustainable disease control is the use of resistant varieties. One of the most important strategies to reduce the impact of this disease is to use cultivars that have resistant to spot blotch Use of resistant cultivar is one of the most important strategy for the control of this disease (Dubin and Duvieller 2000).

\section{Materials and Methods}

The experiment was conducted at main experiment station of Narendra Deva University of Agriculture and Main Experimental Station and Student Instructional Farm (SIF) of Narendra Deva University of Agriculture and Technology, Kumarganj, Faizabad (U.P.) is located in the IndoGangetic plains of eastern Uttar Pradesh at latitude $26.47^{\circ} \mathrm{N}$, longitude $82.12^{\circ}$ and at altitude of $113 \mathrm{~m}$ above the sea level. The experiments were conducted during Rabi 2014-2015 and 2015-16.

The ten days old pure culture of Biopolaris sorokiniana multiplied on potato dextrose Agar and sorghum seeds were used for inoculating on entries. The spore suspension was prepared in sterilized distilled water having a spore load of 50-75 per microscopic field (10x). This suspension was sprayed at 3-
4 leaf stage by using hand atomizer. The second field inoculation was made again in the same manner after the 15 days of the first inoculation.

After inoculation, the entries were regularly watched for recording the observations of disease severity. The first observations were made after ten days of inoculation on ten plants selected randomly. The disease score of each selected plants were recorded by using Kumar et al., (1998) double digit scale (Table 1 and Fig. 1) based on per cent blighted area on the flag and one leaf just below. The maximum disease score of each genotype was recorded finally.

\section{Results and Discussion}

Use of resistant variety is a cheapest and most economical method of disease control. Two hundred fifty varieties (Table 2) were screened under field conditions by double digit scale based on per cent blighted area on the flag and flag-1 leaf at hard dough stages. Three hundred genotypes were evaluated for their reaction to Bipolaris sorokiniana under artificial epiphytotic conditions. Out of these, none of these genotype was found Immune and highly susceptible during both the crop seasons. Twenty eight genotypes such as DL 2283, WBM 3548, HW 1909, HW 5250, DW 1580, SBP 14-42, CSW 104, CSW 107, WBM 3505, WBM 3514, WBM 3549, WR 3029, WR 3030, WR 3031, WR 3032, WR 3033, WR 3034, WR 3036, P 13201, P 13204, P 13232, P 13301, P 13310, P 4113, P 4120, P 4142, P 4143, and WR 1703were found resistant. One hundred thirty two genotypes were found moderately resistant. One hundred three genotypes were found moderately susceptible and thirty seven genotypes were susceptible against spot blotch (B. sorokiniana) disease of wheat in 2014-15 and 2015-16. Similar observations were recorded by other workers. 
Fig.1 Assessment key of Kumar et al., (1998) double digit scale based on per cent blighted area on the flag and flag -1 leaf

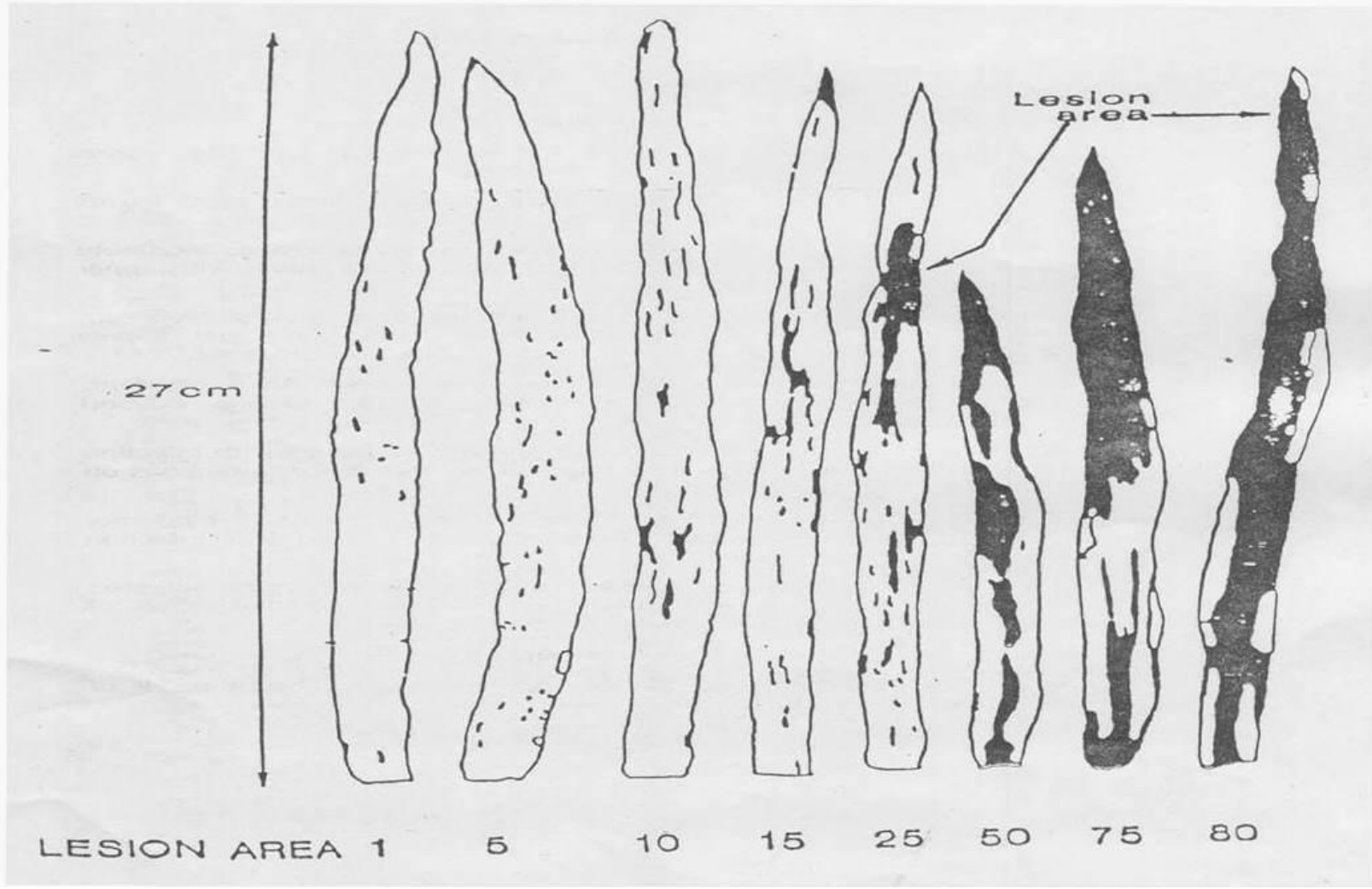

Table.1 The double digit scale, based on per cent blighted area on the flag leaf and one leaf just below given by Kumar et al., (1998)

\begin{tabular}{|c|c|c|c|c|}
\hline \multicolumn{5}{|c|}{ A double digit* scale for appraising blight severity } \\
\hline \multirow{2}{*}{$\begin{array}{c}\text { S. } \\
\text { No. }\end{array}$} & \multicolumn{2}{|c|}{ Severity ${ }^{* *}$} & \multicolumn{2}{|c|}{ Rating } \\
\hline & Flag leaf & Flag-1 leaf & Disease response & Range of value \\
\hline 1. & 0 & $0-1$ & Immune (I) & 00-01 \\
\hline 2. & $1-2$ & $2-4$ & Resistant (R) & $12-24$ \\
\hline 3. & 3-4 & $4-6$ & Moderately Resistant (MR) & $34-46$ \\
\hline 4. & $5-6$ & 6-8 & Moderately susceptible (MS) & $56-68$ \\
\hline 5. & $7-8$ & $8-9$ & Susceptible (S) & $78-89$ \\
\hline 6. & 9 & 9 & Highly susceptible (HS) & 99 \\
\hline \multicolumn{5}{|c|}{$\begin{array}{l}* \text { First and second value respectively, represents per cent blighted area on the flag leaf and } \\
\text { flag-1 leaves. } \\
* * \text { Values } 1,2,3,4,5,6,7,8 \text {, and } 9 \text {, respectively correspond to } 10,20,30,40,50,60,70,80 \text { and } \\
90 \text { per cent blighted area. }\end{array}$} \\
\hline
\end{tabular}


Table.2 Categorization of wheat genotypes against the response of spot blotch disease under artificial disease pressure (2014-15 and 2015-16)

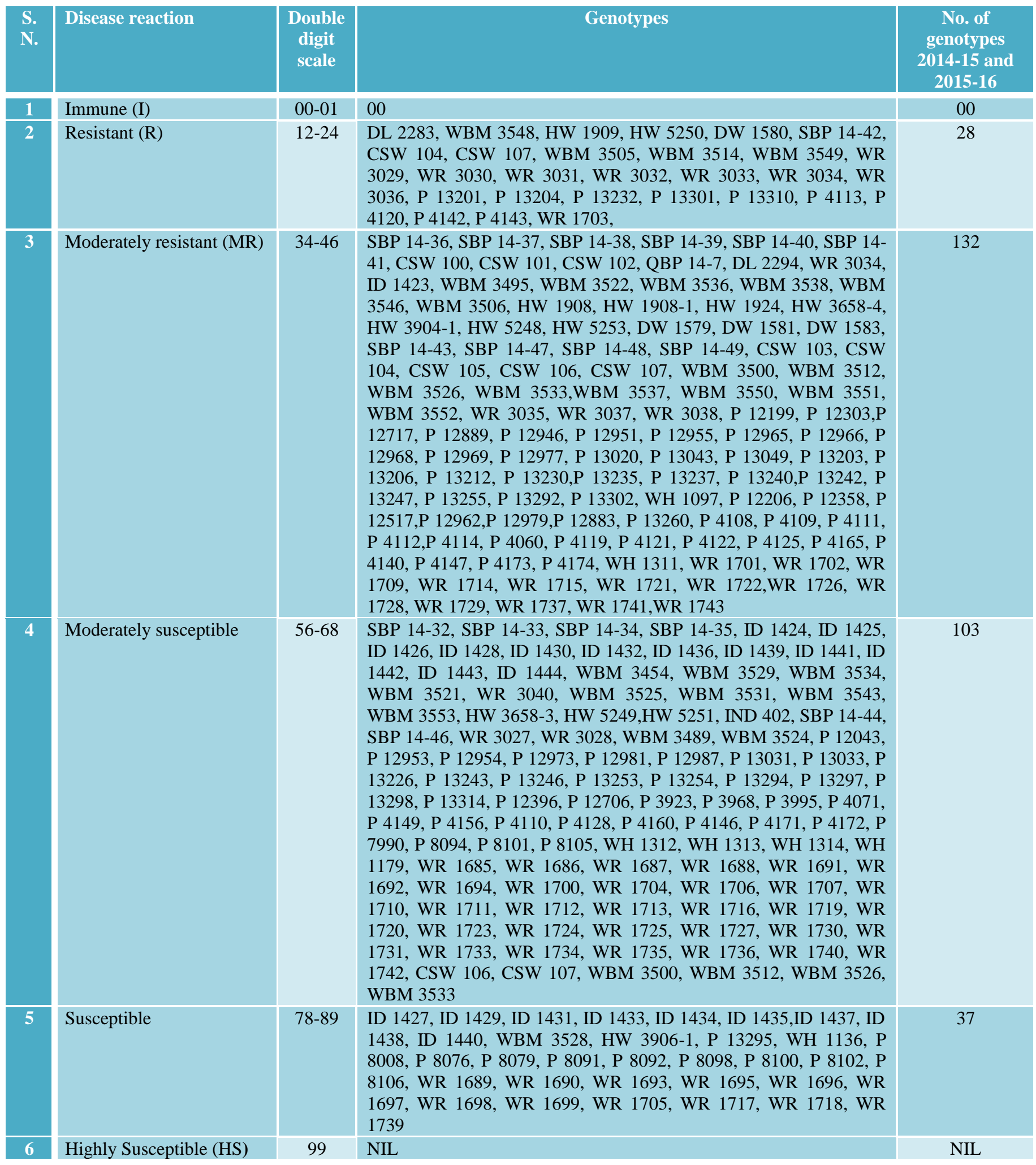


Prem et al., (2008) evaluated 60 wheat cultivars for resistance against Bipolaris sorokiniana and reported VL 818 and TL 8878 resistant to this disease. Dhanbir et al., (2009) evaluated 22 wheat varieties against leaf blight, blotches and black point caused by Alternaria and Helminthosporium under artificial conditions. Out of which genotypes HPW155, HPW 184 and HPW 93 were found resistant to foliar blights.

\section{References}

Anonymous (2016). Project Directorate report (IIW \& BR), Karnal.

Anonymous (2016). United states Department of Agriculture (USDA), Circular Series WAP, 8-16.

Dhanbir, Singh, Akhilesh, Singh, Ravinder Kumar, (2009). Evaluation of wheat genotypes against foliar blights and black point. Res., on Crops, 10(3):705707.

Dubin, H.J. and Duveiller, E. (2000). Helminthosporium leaf blights of wheat: integrated control and prospects for the future. In: proc. Int. conf. integrated
Plant Disease Management for Sustainable Agriculture, New Delhi, 1015 Nov. 1997, vol. (1), Pp. 575-579.

Duveiller, E. and Sharma, R.C. (2009). Genetic improvement and crop management strategies to minimize yield losses in warm non-traditional wheat growing areas due to spot blotch pathogen Cochliobolus sativus. J. Phytopathol., 157: 521-534.

Joshi, A.K., Kumari, M., Singh, V.P., Reddy, C.M., Kumar, S., Rane, J. and Chand, R. (2007). Stay green trait: variation, inheritance and its association with spot blotch resistance in spring wheat (Triticum aestivum L.). Euphytica, 153: 59-71.

Prem, Naresh, Singh, V.K., Biswas, S.K., Kumar, Upesh. (2008). Evaluation of wheat cultivars for Resistant against Biopolaris sorokiniana. Ann. Plant Protection Sci., 16(2): 525-528.

Saari, E.E. (1998). Leaf blight disease and associated soilborne fungal pathogens of wheat in south and south East Asia. CIMMYT, Mexico D.F., pp. 37-51.

\section{How to cite this article:}

Ghanshyam Verma, Shivam Kumar, Chandra Pal and Sheetala Varma. 2018. Evaluation of Wheat Genotypes for Resistance against Foliar Blight Disease. Int.J.Curr.Microbiol.App.Sci. 7(11): 1642-1646. doi: https://doi.org/10.20546/ijcmas.2018.711.186 